\title{
Patient focus
}

Staff can be the most resistant to change. . continuing to treat patients as material for the dentist to 'treat' rather than as customers to be cared for

Mike Grace m.grace.bdj@bda-dentistry.org.uk
W

That exactly does the phrase 'patient focus' mean? Philip Newsome, author of the BDJ book The Patient-Centred Dental Practice suggests that the terms customer care and patient focus mean the same thing. Basically this is an emphasis on providing systems within the practice to offer services that patients are really interested in. Practice focus (rather than patient focus) centres on providing services which the practice is prepared to accommodate and which inconvenience the practice and staff the least.

This type of thinking is really only just penetrating the overall professional consciousness. In the past the attitude has often been that 'patients should be grateful that I take time out to see them' and although this is starting to change, experience suggests we still have a long way to go as a profession. All too often I have attended a full-day series of lectures or a workshop (whether clinical or political) only to have someone from the audience comment at the end of the day that the word 'patient' has yet to be mentioned.

Which brings me back to the subject of this leader — patient focus. Sadly, experience shows that many dental practices continue to behave as they always have, placing the focus of their behaviour on what suits the practice rather than the patient. Perhaps surprisingly, the staff can be the most resistant to change, with receptionists and dental nurses continuing to treat patients as material for the dentist to 'treat' rather than as customers to be cared for. I have experienced and observed patients being treated in a very practice-focused way many times, and some examples will help clarify what I mean.

For instance, a practice focused practice tends to open at times that suit the dentists and/or staff, tends (amazingly) to be annoyed by patients telephoning the practice for advice or help, tends to have no message facility on the answer phone (and worse, closes for lunch), tends to run the appointment book and recall system to suit the practice, and usually cannot provide advice on the cost of treatment either before or during treatment, but simply produces a bill on completion. In contrast, the patient-focused practice tends to find out the ideal opening times for patients and try to accommodate them, tends to provide patients with choices for recall arrangements, tends to advise patients on transport facilities and parking availability, tends to provide telephone cover throughout the working day, tends to have clear prices available for all patients (with all dentists charging the same fees) and tends to check regularly whether the practice is providing appropriate services for patients. In essence, a patient-focused practice listens to the patients and takes appropriate action. In the commercial world this is known as good customer care, and we all recognise the difference when we are on the receiving end.

The good news is that I think the attitude of the profession is starting to change towards a more patient-focused approach, and my perception was strengthened by a visit to the Yorkshire Vocational Training Scheme's Table Clinic day at the beginning of May this year. There were 47 table clinics on display from the four Yorkshire Vocational Training Schemes, each one featuring the project that the trainer and VDP had worked on over the VT year. Just over a quarter of these projects were patient-focused (by my definition) which is a remarkably high percentage, and most of these involved identifying genuine patient requirements (rather than making assumptions) and then taking action to help satisfy those requirements. Now if this approach could find its way into 25 per cent of all the dental organisations throughout the UK (a similar percentage as I found with the VDPs) we would be seeing a revolution in total patient care that would really raise the profile of dentistry. 